\title{
Schwannoma of the Twelfth Cranial Nerve
}

National Cancer Institute

\section{Source}

National Cancer Institute. Schwannoma of the Twelfth Cranial Nerve. NCI Thesaurus.

Code C5434.

A benign schwannoma occurring in the twelfth cranial nerve. 